\title{
A NOTE ON DIFFERENTIAL POLYNOMIALS
}

\author{
A. P. HILLMAN
}

The following theorem indicates to what extent the expression of a differential polynomial ${ }^{1} G$ as an element of the differential ideal determined by $F$ is unique.

Theorem I. Let $F \neq 0, C_{0}, C_{1}, \cdots, C_{s}$ be differential polynomials in the unknowns $y_{1}, \cdots, y_{n}$ with coefficients in an abstract differential field $\mathcal{F}$. Let $F^{(i)}$ be the ith derivative of $F$ and let

$$
C_{0} F+C_{1} F^{\prime}+\cdots+C_{s} F^{(s)}
$$

be identically zero. Then each $C_{i}$ is in the perfect ideal generated by $F{ }^{2}$

We need merely show that any solution $y_{j}=\bar{y}_{j}(j=1, \cdots, n)$, in any extension $\mathcal{F}_{1}$ of $\mathcal{F}$, of the form $F$ is a solution of each $C_{i \cdot}{ }^{3}$ Since this is true if $F$ has no solutions, we may assume that $F$ effectively involves the unknowns. Make the substitution $y_{j}=z_{j}+\bar{y}_{j}$ in (1). Let $A$ consist of the terms of $F$ of lowest degree in the $z_{j}$ and their derivatives. Collecting terms of the same degree, we see that

$$
C_{0}(\bar{y}) A+\cdots+C_{8}(\bar{y}) A^{(s)}=0,
$$

where $C_{i}(\bar{y})$ is the element of $\mathcal{f}_{1}$ obtained by substituting $y_{j}=\bar{y}_{j}$ $(j=1, \cdots, n)$ in $C_{i}$. Let $A$ be of order $p \geqq 0$ in some $z_{k}$ which it effectively involves, let $z_{k, m}$ be the $m$ th derivative of $z_{k}$, and let $S$ be the partial derivative of $A$ with respect to $z_{k, p}$. For $i>0, A^{(i)}$ can be written as $S z_{k, p+i}+B_{i}$, where $B_{i}$ is some form of order less than $p+i$ in $z_{k}$. Now (2) becomes

$$
C_{s}(\bar{y}) S z_{k, p+s}+D=0
$$

where $D$ has order less than $p+s$ in $z_{k}$. Hence $C_{s}(\bar{y})=0$. In turn $C_{s-1}, \cdots, C_{0}$ must vanish for $y_{j}=\bar{y}_{j}$ as desired.

Using the ideas of the above proof together with a uniqueness result of J. F. Ritt, ${ }^{4}$ one can very easily prove the following generalization.

Received by the editors January 4, 1943.

1 For definitions of differential fields, polynomials, and ideals, see H. W. Raudenbush, Ann. of Math. (2) vol. 34 (1933) pp. 509-517.

${ }^{2}$ For a result analogous to Theorem I for ordinary polynomials, see Satz 1 of E. Lasker, Zur Theorie der Moduln und Ideale, Math. Ann. vol. 60 (1905) pp. 20-116.

${ }^{3}$ H. W. Raudenbush, Trans. Amer. Math. Soc. vol. 36 (1934) pp. 361-368.

4 On singular solutions...., Ann. of Math. vol. 37 (1936) pp. 552-617, §§1-3. 
TheORem II. Let $C_{1} P_{1}+\cdots+C_{s} P_{s}$ be identically zero, where the $P_{i}$ are distinct power products each of degree $d>0$ in a nonzero $F$ and its derivatives. Then each $C_{i}$ is in the perfect ideal generated by $F$.

New YoRk City

\section{ON THE NON-EXISTENCE OF ODD PERFECT NUMBERS OF FORM $p^{\alpha} q_{1}^{2} q_{2}^{2} \cdots q_{t-1}^{2} q_{t}^{4}$}

\section{ALFRED BRAUER ${ }^{1}$}

One of the oldest unsolved mathematical problems is the following one: Are there odd perfect numbers ${ }^{2}$ If such a number $n$ exists, it must have the form

$$
n=p^{\alpha} q_{1}^{2 \beta_{1}} q_{2}^{2 \beta_{2}} \cdots q_{t}^{2 \beta t}
$$

where $p, q_{1}, q_{2}, \cdots, q_{t}$ are primes and $p \equiv \alpha \equiv 1(\bmod 4)$. This has been proved by Euler. ${ }^{3}$ Sylvester ${ }^{4}$ obtained estimates for $t$, in particular $t \geqq 4$, and $t \geqq 7$ if $n \neq \equiv 0(\bmod 3)$. Recently, it was shown by R. Steuerwald ${ }^{5}$ that the case $\beta_{1}=\beta_{2}=\cdots=\beta_{t}=1$ is impossible, and by H. J. Kanold ${ }^{6}$ that the same is true for $\beta_{1}=\beta_{2}=\cdots=\beta_{t}=2$. Moreover Kanold proved that $n$ is not perfect if the greatest common divisor $d$ of $2 \beta_{1}+1,2 \beta_{2}+1, \cdots, 2 \beta_{t}+1$ is divisible by $9,15,21$, or 33 , and some similar results. All these results deal with the case $d>1$.

In the following, it will be proved that no odd perfect number $n$ of form $p^{\alpha} q_{1}^{2} q_{2}^{2} \cdots q_{t-1}^{2} q_{t}^{4}$ exists. Here we have $d=1$. For the proof I use

Presented to the Society, April 24, 1943; received by the editors March 1, 1943.

1 The relation of the results of this paper to another paper by H. J. Kanold, Verschärfung einer notwendigen Bedingung für die Existenz einer ungeraden vollkommenen Zahl, J. Reine Angew. Math. vol. 184 (1942) pp. 116-124, will be considered in an addendum to be published in the December Bulletin.

2 For the history of the problem see Dickson, History of the theory of numbers, vol. 1, 1919, pp. 1-33.

3 Commentationes arithmeticae collectae, vol. 2, Tractatus de numerorum doctrina 1849, p. 514; Opera postuma, vol. 1, 1862, pp. 14-15.

4 Sur l'impossibilité de l'existence d'un nombre parfait impair qui ne contient pas au moins 5 diviseurs premiers distincts, C. R. Acad. Sci. Paris vol. 106 (1888) pp. 522-526; Collected mathematical papers, vol. 4, 1912, pp. 611-614. Sur une classe spéciale des diviseurs de la somme d'une sêrie géométrique, C. R. Acad. Sci. Paris vol. 106 (1888) pp. 446-450; Collected mathematical papers, vol. 4, 1912, pp. 607-610.

- Verschärung einer notwendigen Bedingung fïr die Existenz einer ungeraden vollkommenen Zahl, Sitzungsberichte der mathematisch-naturwissenschaftlichen Abteilung der Bayerischen Akademie der Wissenschaften zu München, 1937, pp. 68-72.

- Untersuchungen uber ungerade vollkommene Zahlen, J. Reine Angew. Math. vol. 183 (1941) pp. 98-109. 